\title{
Mercury Contamination in the Topsoil and Subsoil of Urban Areas of Beijing, China
}

\author{
Xing-Hong Li • Hang-Xin Cheng • Chuan-Dong Zhao • \\ Xiao-Bai Xu
}

Received: 25 January 2010/Accepted: 8 June 2010/Published online: 20 June 2010

(C) Springer Science+Business Media, LLC 2010

\begin{abstract}
Mercury contamination is a serious problem in Chinese cities. In the present study, mercury contamination was evaluated in topsoil and subsoil samples collected in an urban area of Beijing. The level of total mercury in topsoil ranged from 12.1 to $8,487 \mathrm{ng} \mathrm{g}^{-1}$, and a significant correlation $(R=0.58145, p<0.0001)$ with polycyclic aromatic hydrocarbons was observed. Higher levels were generally observed in the suburbs and urban centers, with the highest levels being observed in the urban centers. The fraction of water soluble, ion exchangeable, $\mathrm{Fe}-\mathrm{Mn}$ in the oxide-bound and organic phase was $0.78 \%, 0.18 \%, 0.25 \%$ and $3.42 \%$, respectively. For subsoils, the level of total mercury ranged from 7.0 to $924.6 \mathrm{ng} \mathrm{g}^{-1}$, and the higher levels were primarily located in the suburbs. This study showed that mercury has possibly affected the environmental quality of soil and groundwater in urban areas of Beijing.
\end{abstract}

Keywords Mercury - Speciation · Topsoil - Subsoil · PAHs · Sources

With the expansion of urbanization and accompanying industrial activities, emissions of pollutants in urban areas have been increasing, which has led to deterioration of air,

\section{X.-H. Li · X.-B. Xu}

State Key Laboratory of Environmental Chemistry and EcoToxicology, Research Center for Eco-Environmental Sciences, Chinese Academy of Sciences, P. O. Box 2871, 100085 Beijing, China

H.-X. Cheng $(\bowtie) \cdot$ C.-D. Zhao

Institute of Geophysical and Geochemical Exploration, Chinese

Academy of Geological Science, 065000 Langfang, China

e-mail: chxrcees@163.com soil and water quality (Wong et al. 2006). Heavy metals, radionuclides, chlororganic compounds and polycyclic aromatic hydrocarbons are considered to be the most common contaminants. As an important sink of these pollutants, the status of urban soils is strongly related to human health in towns and cities (Boyd et al. 1999). Due to the prolonged presence and ecological toxic effect of heavy metals, it is important to study their environmental levels and behaviors. Mercury, which is one of the most important trace elements emitted into the urban environment, has attracted a great deal of attention due to its persistence, toxicity and bioaccumulation. It has been reported that mercury contamination is a serious problem in Chinese cities (Zhang and Wong 2007). Beijing, which is the capital of China, has a population of over eight million and is the center of its economy, culture and politics; however, it is also a heavy industrial city. Specifically, the industry in Beijing primarily consists of coal mining, thermal energy development, the metallurgical industry, and industries that produce machinery, chemicals, and iron and steel. As a result, mercury emissions are widespread in Beijing. Specifically, the total gaseous mercury in the atmosphere of Beijing has been reported to range from 6.2 to $24.7 \mathrm{ng} \mathrm{m}^{-3}$ (Liu et al. 2002), which is much higher than the global background range of $1-3 \mathrm{ng} \mathrm{m}^{-3}$ (Tayban and Preston 2005). Similarly, the mercury content of dust and soil has reached $0.053-1.378$ and $0.019-0.966 \mathrm{mg} \mathrm{kg}^{-1}$, respectively (Zhang et al. 2006). Although there has been some information regarding mercury in the soils near factories and some unique locations such as south-east suburban areas in Beijing (Liu et al. 2002; Tayban and Preston 2005; Zhang et al. 2006; Hu et al. 2006), its levels and distribution throughout the city have not been reported. Therefore, this systematic investigation of mercury in the topsoil and subsoil of Beijing was conducted using the grid 
sampling method in an attempt to understand mercury pollution for the entire city. The dataset generated here will provide guidance for formulating future environmental planning and management strategies.

\section{Materials and Methods}

A total of 285 topsoil samples $(0-20 \mathrm{~cm})$ and 63 subsoil samples $(150-180 \mathrm{~cm})$ were collected from the study area (see Fig. 1a, b). For topsoil samples, the study area was divided into regular grids of $1.0 \times 1.0 \mathrm{~km}$, and five subsamples were taken in the four corners and the center of each square block and then mixed thoroughly to give a $1.0 \mathrm{~kg}$ composite sample representative of each sampling grid. Subsoil samples were collected in a fashion similar to that of topsoils; however, the grids were $4.0 \times 4.0 \mathrm{~km}$. The sampling locations covered $1,080 \mathrm{~km}^{2}$, and the distribution was relatively uniform based on a grid design that covered an approximately equal longitude and latitude. The area within the fourth Ring Road was classified as an urban center area including the sample numbers in subsoil from $31-34,38-41$ to $45-48$, or in topsoil from $218-225,239-$ 246, 260-267, 281-288, 302-309, 323-330 to 344-351. Topsoil samples 46-123 and subsoil samples 1-14 were collected from areas considered to be rural, while the rest were collected from areas defined as suburban.

The soil samples were air-dried in the dark at room temperature, thoroughly mixed, sieved to 30 mesh, and then transferred to pre-cleaned amber glass sample containers and stored at $-4^{\circ} \mathrm{C}$ until subsequent processing. Prior to analysis, the soil was ground and then digested with $\mathrm{HNO}_{3}$ and $\mathrm{H}_{2} \mathrm{O}_{2}$ using Method 3050B (USEPA 1996), after which the total mercury was determined using an atomic fluorescence spectrometer (2202, Haiguang Co., Beijing, China). Sequential chemical fractionation based on the procedures of Tessier et al. (1979) and Keller and Vedy (1994) was used to fractionate the mercury in water soluble (WS), ion exchangeable, Fe-Mn oxide-bound (Fe-Mn OX), and organic (OM) forms in the suburban and rural topsoil samples. For quality assurance/control, a standard reference material, GSS-1 soil, obtained from the Center for National Standard Reference Material of China, was used to spike $8 \%$ of each batch of samples and $6 \%$ of each batch consisted of duplicate samples. Soil properties were analyzed based on the method recommended by the Soil Science Society of China.

\section{Results and Discussion}

The statistics describing the mercury concentrations are presented in Table 1. The data approached a lognormal

\section{A}

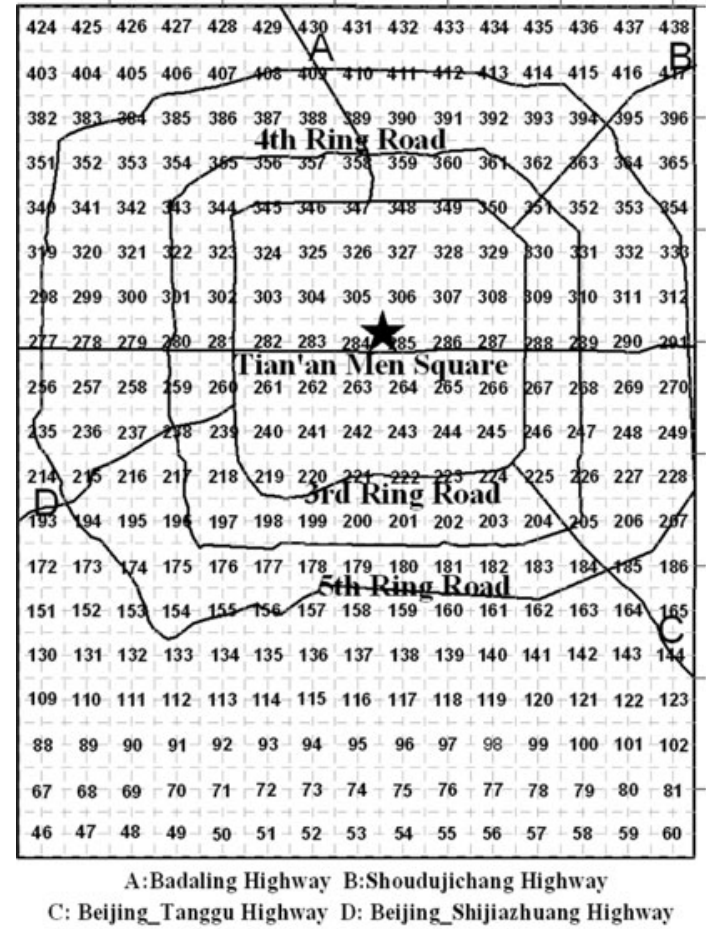

B

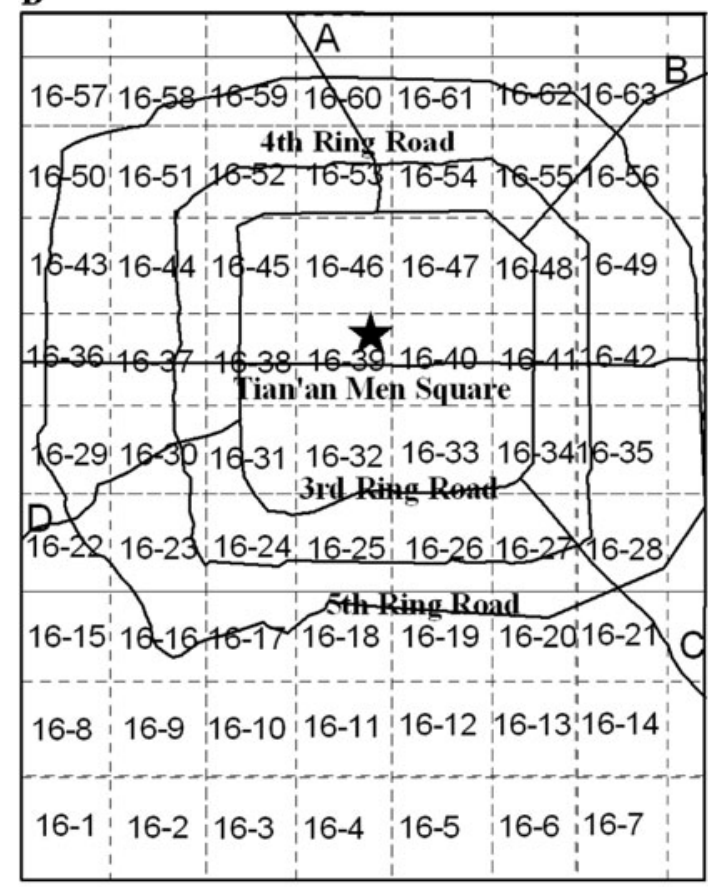

A:Badaling Highway B:Shoudujichang Highway

C: Beijing_Tanggu Highway D: Beijing_Shijiazhuang Highway

Fig. 1 The sampling layout. a Geographical location of topsoil samples, b geographical location of subsoil samples

distribution except for samples collected from the rural deep layer soil, which showed a normal distribution; therefore, the median values were used in the following discussion. The mercury background levels in the soils of 
Table 1 Mercury concentration in topsoil and subsoil samples in Beijing ( $\mathrm{ng} \mathrm{g}^{-1}$ )

\begin{tabular}{|c|c|c|c|c|c|c|c|c|}
\hline & Min. & Max. & Median & Mean & S.D. & C.V. & PENBV & PENSV \\
\hline \multicolumn{9}{|l|}{ Topsoil } \\
\hline Rural & 12.1 & 934.7 & 78.4 & 109.3 & 125.8 & 115.1 & 48 & $17 *$ \\
\hline Suburban & 15.1 & 3738.0 & 337.7 & 466.8 & 494.3 & 105.9 & $92^{*}$ & $83^{*}$ \\
\hline Center & 66.7 & 8487.0 & 462.0 & 730.2 & 1101.9 & 150.9 & $99^{*}$ & $96^{*}$ \\
\hline Whole city & 12.1 & 8487.0 & 471.3 & 471.3 & 715.2 & 151.8 & $85^{*}$ & $72 *$ \\
\hline \multicolumn{9}{|l|}{ Deep soil } \\
\hline Rural & 7.0 & 99.5 & 17.6 & 24.0 & 23.0 & 95.9 & $7^{*}$ & $0 *$ \\
\hline Suburban & 12.1 & 924.6 & 44.2 & 129.6 & 215.7 & 166.3 & 34 & 21 \\
\hline Center & 14.1 & 293.0 & 39.8 & 71.5 & 76.9 & 107.6 & 30 & $15^{*}$ \\
\hline Whole city & 7.0 & 924.6 & 34.2 & 87.7 & 157.3 & 179.4 & 27 & 14 \\
\hline
\end{tabular}

PENBV Percentage exceeding the natural background value of mercury in the soil environment of the Beijing Region $\left(80 \mathrm{ng} \mathrm{g}^{-1}\right) ; P E N S V$ Percentage exceeding the Natural Standard for Soil Environment Quality I of mercury $\left(150 \mathrm{ng} \mathrm{g}^{-1}\right)$; Significant at the $0.05(*)$ level of probability when compared with the reference values

Beijing (NBV, Environmental monitoring of China, 1994) and the Natural Standard Value for Soil Environment Quality I of mercury (NSV, GB15618-1995) were used as reference values for unpolluted soil. For topsoils, the median concentration of mercury in rural soils (78.4 $\mathrm{ng} \mathrm{g}^{-1}$ ) was near the NBV $\left(80 \mathrm{ng} \mathrm{g}^{-1}\right)$ and about twofold lower than the NSV (150 $\left.\mathrm{ng} \mathrm{g}^{-1}\right)$, indicating that most soil samples in rural areas were safe for agricultural production. For suburban and urban areas, the median values were significantly higher than the NBV $(p<0.05)$, with some values such as those at sites 383, 438, 238, 241, 305, 306 and 307 exceeding the highest critical value for safe soil application (1.5 $\mathrm{mg} \mathrm{kg}^{-1}$, GB15618-1995). When compared to other cities in the world, the concentration fell within the range of urban soils from developed countries (Zhang et al. 2006). However, when compared to other cities in China such as Tibet, Shenzhen, Taiyuan, Shanghai and Chongqing, the mercury levels in the topsoil of Beijing were much higher (Zhang and Wong 2007). One systematic investigation of the environmental quality of topsoil in Beijing was conducted in 1987 with a sampling density of $1.25 \mathrm{~km}^{2}$. The results of that study revealed that the level of mercury ranged from 40 to $62,600 \mathrm{ng} \mathrm{g}^{-1}$, and that the average was $1,355 \pm 3,083 \mathrm{ng} \mathrm{g}^{-1}$, which was about $287 \%$ higher than the levels observed in the present study. However, contrary to other recent studies conducted to evaluate mercury in the topsoil of Beijing (industrial center, 0.07-2.75 $\mathrm{mg} \mathrm{kg}^{-1}$, Liu et al. 1998; 0.01-0.966 $\mathrm{mg} \mathrm{kg}^{-1}$, Zhang et al. 2006), mercury level fell in the range. For subsoil, a one-sample $t$-test showed that mercury in most samples was close to the NBV or significantly lower than the background value, indicating that mercury has a minimal effect on the agricultural soil and underground water in the area. However, the concentration of mercury in some samples from suburban soils was as high as $924.6 \mathrm{ng} \mathrm{g}^{-1}$; therefore, these areas warrant greater attention.

The spatial maps of mercury in topsoil and subsoil samples were displayed in Fig. 2a, b. For topsoil samples (Fig. 2a), the 90 angle urban center region from South 3rd Ring Road to West 3rd Ring Road were the most seriously contaminated zones. There were also some areas with elevated mercury concentrations between the West 4th Ring Road and the West 5th Ring Road of the suburban portion of Beijing. Conversely, the rural zones had lower concentrations of mercury. The median mercury concentration in different regions supported the spatial distribution characteristics, which occurred in the following order: urban center soil $>$ suburban soil $>$ rural soil. One way analysis of variance (ANOVA) indicated that the concentration of mercury in urban center topsoil, suburban topsoil and rural topsoil differed significantly from each other, which agreed with the reports of Liu et al. (1998) and Zhang et al. (2006), who found that mercury concentrations in top-soils became progressively lower from the center of the city to the suburbs and also fitted with the distribution of mercury in the atmosphere (Liu et al. 2002). The regional distribution characteristics of mercury were probably closely related to the orientation of the functional areas of Beijing. Specifically, the central area is dominant, with a higher population and larger number of vehicles, as well as many ancient buildings that are thousands of years old. The suburban region outside of the 4th Ring-Road is notorious as an area of heavy industry that contains facilities such as the Shoudu Steel Iron Company and the Beijing Chemistry Factory and Beijing Coking Factory. The rural region in the southern area is a well-known agricultural area. The high level of mercury in the urban 

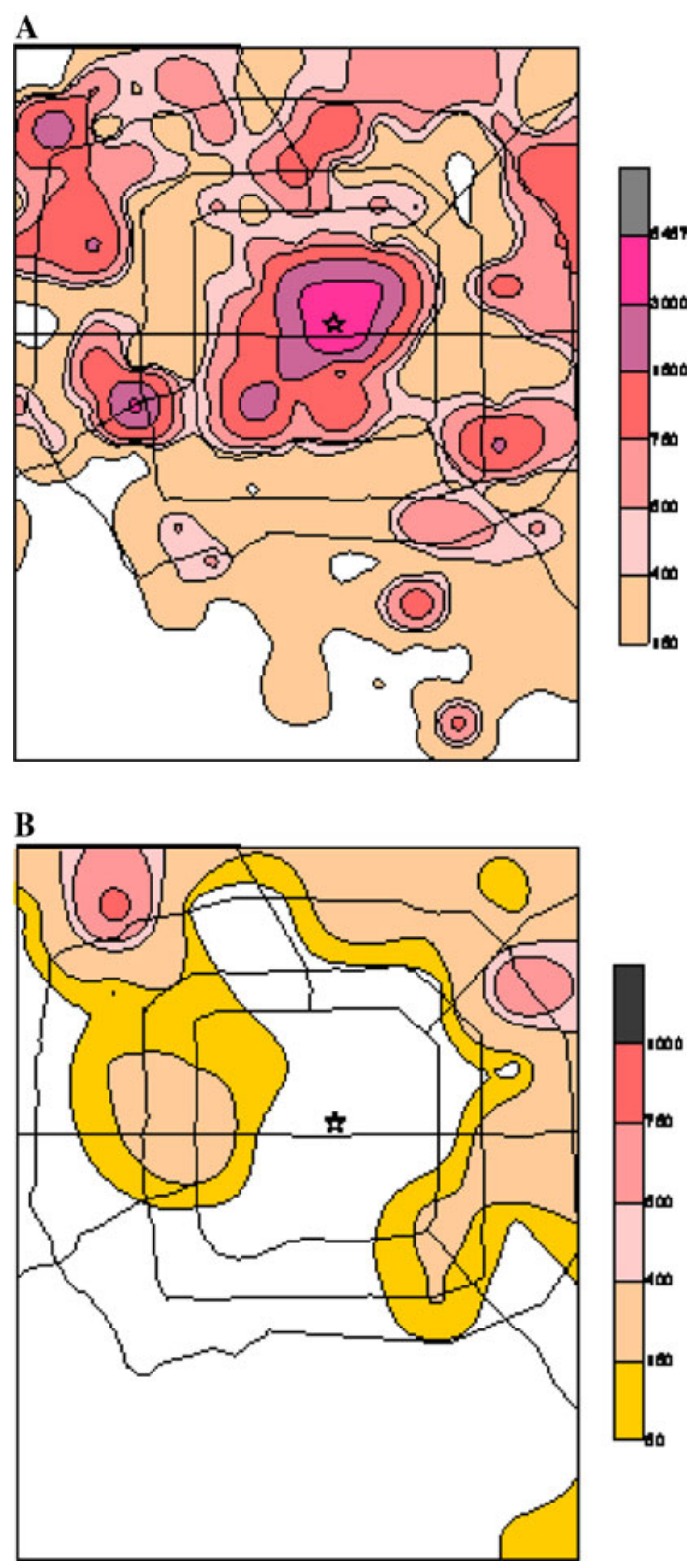

Fig. 2 Mercury distribution in topsoil and subsoil

center was likely attributed to anthropogenic activities, while the scattered areas of high mercury levels might be attributed to industrial activities as point sources. The contamination of mercury in rural regions was low because they are primarily used for agricultural production.

For subsoils (Fig. 2b), the areas with the highest levels of mercury were not located in the urban center, but rather scattered throughout the suburban area, and the median mercury concentrations occurred in the following order: suburban soil $>$ urban soil $>$ rural soil. However, the distribution characteristics of mercury in the suburbs were similar to those in topsoil, which indicates that the transfer of mercury occurred from the top down. The soil type in the suburban areas is mainly sandy loam and silt loam, which would result in easy leaching of mercury from the topsoil into the subsoils. As a result, increased attention should be paid to the environmental quality of the suburban soils due to the threat to ground water.

In addition to natural sources of mercury, incomplete combustion from fossil fuels is known to be one of the most important sources of environmental mercury. Indeed, it has been estimated that about $75 \%$ of the total mercury emission worldwide can be attributed to the combustion of fossil fuels, especially in China, India and South and North Korea (Pacyna et al. 2003; Garban et al. 2002). It should be noted that the regional distribution of PAHs (Ma et al. 2005; Li et al. 2006) is similar to that of the distribution of mercury observed in the present study. Correlation analysis of both PAHs and total mercury revealed a lognormal positive correlation $(R=0.58145, p<0.0001)$, which reflected the important contribution of incomplete combustion of fossil fuels to total mercury in topsoil in Beijing. This was consistent with a report by Streets et al. (2005), who estimated that mercury emission in Beijing was approximately $5.11 \mathrm{t}, 2.02 \mathrm{t}$ and $1.70 \mathrm{t}$ from coal combustion, non-ferrous metals smelting and other sources, respectively. Their findings indicate that anthropogenic activities such as coal combustion, metals smelting and miscellaneous activities were the predominant sources of mercury in topsoil in Beijing.

To assess the effects of mercury on soil environmental quality in Beijing, the pollution index (PI) was used. PI is the ratio of the mercury concentration to the background concentration (BC) in soils. The PI was classified as either low pollution $(\mathrm{PI} \leq 1)$, moderate pollution $(1<\mathrm{PI} \leq 3)$ or high pollution (PI $\geq 3$ ). For top soils as a whole, the PI varied greatly from 0.2 to 106.1 , and over $59 \%$ of the samples had a value higher than 3 . The average PI in rural topsoil was $1.4 \pm 1.6$; however, $52 \%$ of the samples had a PI value $<1$. The PI in suburban topsoil was $5.7 \pm 5.0$, while $70 \%$ of the samples had a value $\geq 3$. The PI in urban center topsoil was $9.6 \pm 14.5$ and was $>1$ for all samples. These results indicate that topsoil in Beijing has been severely impacted by mercury, especially in urban centers and suburban areas. For subsoil samples, mercury in most samples was classified as low, with a PI $<1$ being observed in $92 \%$ of the samples. These findings suggest that there is little or no threat to the soil environment and the groundwater. However, it should be noted that some areas in the northern portion of the study area had a PI value $>3$.

The severity of pollution depends on the total heavy metal content of the soil, as well as the proportion of their mobile and bioavailable forms. Sequential fractionation schemes can provide qualitative evidence of the chemical forms of trace elements and indirect evidence of their 
bioavailability (Ma and Rao 1997). In the present study, the fraction of mercury in the water soluble, ion exchangeable, Fe-Mn oxide-bound and organic phases in topsoil was $0.78 \%, 0.18 \%, 0.25 \%$ and $3.42 \%$, respectively. The percentage of mercury in the water soluble and ion exchangeable phase was less than $1 \%$, indicating low mobility and bioavailability of mercury in topsoil in Beijing. Although the Fe-Mn oxide-bound and organic phase, which had less reactivity in soils, only accounted for $3.67 \%$ of the total mercury, these phases are easily activated in the short term when environmental conditions or soil physicochemical properties change. Most of the mercury in the soil was present in the inactive form, indicating that the ecological effect of mercury was not significant under the present conditions. However, due to the high total mercury levels, the fractions of mercury indicate the probable existence of a chemical time bomb in the soil of Beijing.

The results of this study demonstrate that Beijing has been affected by human activity, which has led to the high accumulation of mercury in topsoil, indicating that mercury should be one of the major compounds considered during environmental management. Only a small percentage of mercury was present in active chemical forms, indicating that it has low mobility and little bioavailability; however, the high total mercury levels suggest that there is a chemical time bomb in the soil that could lead to the release of a great deal of mercury when external conditions change. Areas with higher levels of mercury were primarily concentrated in the suburban area and urban center of Beijing, indicating that these areas warrant further consideration The significant correlation with PAHs indicated the important contribution of anthropogenic activities such as coal combustion and metals smelting to mercury contamination. In subsoils, the mercury level primarily fell in the range of the background value. The similar regional distribution of mercury in the suburban area between topsoils and subsoils indicates the occurrence of transfer from the top down, suggesting a potential threat to the underground water. The data generated in this study will be helpful for the development of effective approaches designed to eliminate/reduce mercury contamination and the reuse of land.

Acknowledgements We acknowledge financial support of this work by State Science and Technology Council Program "973" of the
People's Republic of China (No. G1999045707) and the National Natural Science Foundation of China (20607026, 20877092).

\section{References}

Boyd HB, Pederson F, Cohr KH, Damborg A, Jakobsen BM, Kristensen P, Samsoe-Petersen L (1999) Exposure scenarios and guidance values for urban soil pollutants. Regul Toxicol Pharmacol 30:197-208

Garban B, Blanchoud H, Motelay-Massei A, Chevreuil M, Ollivon D (2002) Atmospheric bulk deposition of PAHs onto France: trends from urban to remote sites. Atmos Environ 36:5395-5403

Hu KL, Zhang FR, Hong L, Feng H, Li BG (2006) Spatial patterns of soil heavy metals in urban-rural transition zone of Beijing. Pedosphere 16:690-698

Keller C, Vedy JC (1994) Distribution of copper and cadmium fractions in two forest soils. J Environ Qual 23:987-999

Li XH, Ma LL, Liu XF, Fu S, Cheng HX, Xu XB (2006) Polycyclic aromatic hydrocarbon in urban soil from Beijing, China. J Environ Sci China 18:944-950

Liu JH, Wang WA, Peng A (1998) Pollution and sources of Hg in top soil in two district of Beijing city. Acta Scientiae Circumstantiae 18:331-336

Liu SL, Nadim F, Perkins C, Carley RJ, Hoag GE, Lin YH (2002) Atmospheric mercury monitoring survey in Beijing, China. Chemosphere 48:97-107

Ma LQ, Rao GN (1997) Chemical fractionation of cadmium, copper, nickel, and zinc in contaminated soils. J Environ Qual 26:259264

Ma LL, Chu SG, Wang XT, Cheng HX, Liu XF, Xu XB (2005) Polycyclic aromatic hydrocarbons in the surface soils from outskirts of Beijing, China. Chemosphere 58:1355-1363

Pacyna JM, Pacyna EG, Steenhuisen F, Wilson S (2003) Mapping 1995 global anthropogenic emissions of mercury. Atmos Environ 37((Suppl 1)):109-117

Streets DG, Hao JM, Wu Y, Jiang JK, Chan M, Tian HZ, Feng XB (2005) Anthropogenic mercury emissions in China. Atmos Environ 39:7789-7806

Tayban NBAB, Preston MR (2005) Atmospheric vapour phase and particulate phase mercury in a coastal desert climate. J Environ Monit 7:977-982

Tessier A, Campbell PGC, Bisson M (1979) Sequential extraction procedure for the speciation of particulate trace metals. Anal Chem 51:844-851

Wong CSC, Li XD, Thornton I (2006) Urban environmental geochemistry of trace metals. Environ Pollut 142:1-16

Zhang L, Wong MH (2007) Environmental mercury contamination in China: sources and impacts. Environ Int 33:108-121

Zhang XM, Luo KL, Sun XZ, Tan JA, Lu YL (2006) Mercury in the topsoil and dust of Beijing City. Sci Total Environ 368: 713-722 